\section{Elevated cell proliferation and VEGF production by high-glucose conditions in Müller cells involve XIAP}

Y Sun ${ }^{1}$, D Wang $^{2}, \mathrm{~F} \mathrm{Ye}^{3}$, D-N Hu ${ }^{4,5}, \mathrm{X} \mathrm{Liu}^{1}$, $\mathrm{L}_{\text {Zhang }}{ }^{1}, \mathrm{~L} \mathrm{Gao}^{6}$, E Song ${ }^{1}$ and DY Zhang ${ }^{3}$

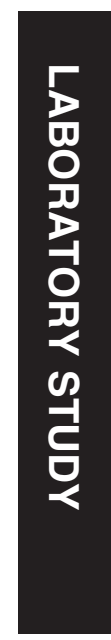

mediate a series of pathological changes induced by high-glucose conditions in Müller cells. Therefore, embelin could be a potential agent for the prevention and treatment of diabetic retinopathy.

Eye (2013) 27, 1299-1307; doi:10.1038/eye.2013.158;

published online 9 August 2013

Keywords: high glucose; retinal Müller cells; protein pathway array; embelin; XIAP

\section{Introduction}

Diabetic retinopathy is one of the main leading causes of vision loss in working-age people worldwide. ${ }^{1}$ Intraocular neovascularization has been recognized to promote the development of diabetic retinopathy. ${ }^{2}$ The vascular endothelial growth factor (VEGF) family and its receptor system, by endogenously producing vascular cytokines, contribute to angiogenesis, vasodilatation, and increased microvascular permeability. ${ }^{3,4}$ In recent years, the development and commercialization of anti-VEGF drugs have revolutionized the therapy of patients with intraocular neovascularization. ${ }^{5}$ Nevertheless, the precise mechanism underlying the regulation of VEGF protein expression in intraocular angiogenesis of diabetic retinopathy remains unclear.

Müller cells, the principal retinal glia, have several important roles both in normal and disease states. ${ }^{6-8}$ Reactive gliosis including hypertrophy, enlargement of soma, and proliferation are the most obvious pathological changes that occur in Müller cells during diabetes. ${ }^{9,10}$ Moreover, increased VEGF expression in Müller cells under hyperglycemic conditions is one of the major contributors to
'Department of Ophthalmology, The First Hospital of Jilin University, Changchun, China

${ }^{2}$ Department of General Jilin University, Changchun, China

${ }^{3}$ Department of Pathology, Mount Sinai School of Medicine, New York, NY, USA

${ }^{4}$ Department of Ophthalmology, New York Medical College, New York, NY, USA

${ }^{5}$ Tissue Culture Center, New York Eye and Ear Infirmary, New York, NY, USA

${ }^{6}$ Department of Oncology, The First Hospital of Jilin University, Changchun, China

Correspondence:

E Song, Department of Ophthalmology, The First Hospital of Jilin University, Changchun 130021, China. Tel: + 8643188782351 ; Fax: + 8643188782251 E-mail: sunny20121023 @163.com or DY Zhang, Department of Pathology, Mount Sinai School of Medicine, New York, NY 10029, USA. Tel: + 1212659 8173; Fax: + 12126598230 E-mail: david.zhang@mssm.edu

Received: 14 January 2013 Accepted in revised form: 27 June 2013 Published online: 9 August 2013 Surgery, The First Hospital of 
pathological intraocular neovascularization. ${ }^{11,12}$ Therefore, exposing the potential mechanism of glucoseinduced VEGF expression in Müller cells is essential to reveal the underlying neovascularization in diabetic retinopathy.

In this study, we investigated the potential signaling pathways and networks that are altered under highglucose conditions using protein pathway array (PPA) in an in vitro Müller cell model. PPA can screen the global changes both in protein expression and activation (ie, phosphorylation), and hence it is a strong tool to investigate cell proliferation, apoptosis, survival, energy metabolism, and stress response. In addition, we studied X-linked inhibitor of apoptosis protein (XIAP)-mediated cell proliferation and VEGF production by high-glucose conditions in Müller cells.

\section{Materials and methods}

\section{Chemicals and drugs}

A 50-mM stock solution of embelin (Sigma, St Louis, MO, USA) was prepared with dimethyl sulfoxide (DMSO; Sigma) and stored at $-20{ }^{\circ} \mathrm{C}$ before use. The stock solution was diluted using culture medium to final concentrations of 0-60 $\mu \mathrm{m}$. D-glucose (Fisher Scientific, Fair Lawn, NJ, USA) was prepared using serum-free Dulbecco's Modified Eagle's Medium (DMEM) to final concentrations of $5,10,25$, and $50 \mathrm{mM}$.

\section{Müller cell culture}

Isolation and culture of Müller cells from SpragueDawley (SD) rats were performed according to the methods described previously. ${ }^{13}$ Briefly, SD rats were killed, and the eyeballs were immediately enucleated under aseptic conditions. The cornea, lens, vitreous, retinal pigmented epithelium (RPE), and nonretinal tissue were removed. Retinas were minced into $1 \times 1 \mathrm{~mm}^{2}$ pieces and filtered through $30 \mu \mathrm{m}$ nylon mesh after incubating with $0.25 \%$ trypsin at $37^{\circ} \mathrm{C}$ for $30 \mathrm{~min}$. The filtrate was then collected and centrifuged at 500 r.p.m. (or $375 \times g$ ) for $5 \mathrm{~min}$. Müller cells were seeded onto a 6-cm tissue culture dish in DMEM containing $20 \%$ heat-inactivated fetal bovine serum, $2 \mathrm{mM}$ L-glutamine, $2 \mathrm{mM}$ sodium pyruvate, $20 \mathrm{mM}$ 4-(2-hydroxyethyl)-1piperazineethanesulfonic acid, $100 \mu \mathrm{g} / \mathrm{ml}$ streptomycin, and $100 \mathrm{U} / \mathrm{ml}$ penicillin at $37^{\circ} \mathrm{C}$ in a humidified $5 \% \mathrm{CO}_{2}$ atmosphere. After $24 \mathrm{~h}$ of incubation, the DMEM was changed, and nonattached cells were discarded. Müller cells continued to grow in DMEM. The culture medium was replaced every 3 days. Cells were dissociated from the culture dish with $0.25 \%$ trypsin and EDTA by incubation at $37^{\circ} \mathrm{C}$. Cells at the third passage were used for the subsequent experiments. A Müller cell was confirmed using transmission electron microscopy, which showed characteristic cytoplasmic intermediate filaments as shown in Figure 1a.

\section{Cell proliferation}

The MTT assay (3, 4, 5-dimethylthiazol-2, 5-diphenyltetrazolium bromide; Sigma) was performed to determine the effect of high-glucose conditions and embelin on Müller cell proliferation. ${ }^{14}$ Approximately $5 \times 10^{3}$ Müller cells at the third passage were seeded onto each well of a 96-well plate and incubated for $24 \mathrm{~h}$ in serum-free DMEM. Cells were incubated in the absence or presence of high-glucose conditions or embelin for an additional $72 \mathrm{~h}$ in serum-free DMEM. Next, $10 \mu \mathrm{l}$ of MTT solution at $5 \mathrm{mg} / \mathrm{ml}$ was added to each well. Cells were incubated for an additional $3 \mathrm{~h}$, and the supernatant was discarded. Finally, $100 \mu \mathrm{l}$ of DMSO was added to each well to dissolve the precipitate. Optical density was measured at a wavelength of $570 \mathrm{~nm}$ using an EL $x 800$ microplate reader (Bio-Tek Instruments, Winooski, VT, USA).

\section{Protein pathway array}

Müller cells $\left(1 \times 10^{6}\right)$ were cultured in $10-\mathrm{cm}$ dishes in serum-free DMEM medium for $24 \mathrm{~h}$. Cells were then treated with either $50 \mathrm{mM}$ glucose or $50 \mathrm{mM}$ glucose plus $60 \mu \mathrm{m}$ embelin for $72 \mathrm{~h}$. Total proteins from the cell culture were extracted using a $1 \times$ cell lysis buffer (Cell Signaling Technology, Danvers, MA, USA) containing $20 \mathrm{mM}$ Tris- $\mathrm{HCl}$ ( $\mathrm{pH} 7.5$ ), $150 \mathrm{mM} \mathrm{NaCl}, 1 \mathrm{mM}$ $\mathrm{Na}_{2}$ EDTA, $1 \mathrm{mM}$ EGTA, 1\% Triton, $2.5 \mathrm{mM}$ sodium pyrophosphate, $1 \mathrm{mM} \beta$-glycerophosphate, $1 \mathrm{mM}$ $\mathrm{Na}_{3} \mathrm{VO}_{4}$, and $1 \mu \mathrm{g} / \mathrm{ml}$ leupeptin in the presence of $1 \times$ proteinase inhibitor cocktail (Roche Applied Science, Indianapolis, IN, USA) and $1 \times$ phosphatase inhibitor cocktail (Roche Applied Science). A total of $300 \mu \mathrm{l}$ of lysis buffer was added to each culture plate, and the cell monolayer was removed from the dish using a scraper. The lysate was sonicated twice for $15 \mathrm{~s}$ each time, and then it was centrifuged at 14000 r.p.m. for $30 \mathrm{~min}$ at $4{ }^{\circ} \mathrm{C}$. The protein concentration was determined using the BCA Protein Assay kit (Pierce, Rockford, IL, USA). The cell extract containing $300 \mu \mathrm{g}$ of protein was loaded in one well across the entire width of a SDS-polyacrylamide gel electrophoresis (SDS-PAGE; 10\% acrylamide) gel as described previously. ${ }^{14,15}$ After electrophoretic separation, proteins were transferred electrophoretically to a nitrocellulose membrane. The membrane was then blocked for $1 \mathrm{~h}$ with $5 \%$ milk or $3 \%$ bovine serum albumin at room temperature. Next, the membrane was clamped with a western blotting manifold that 


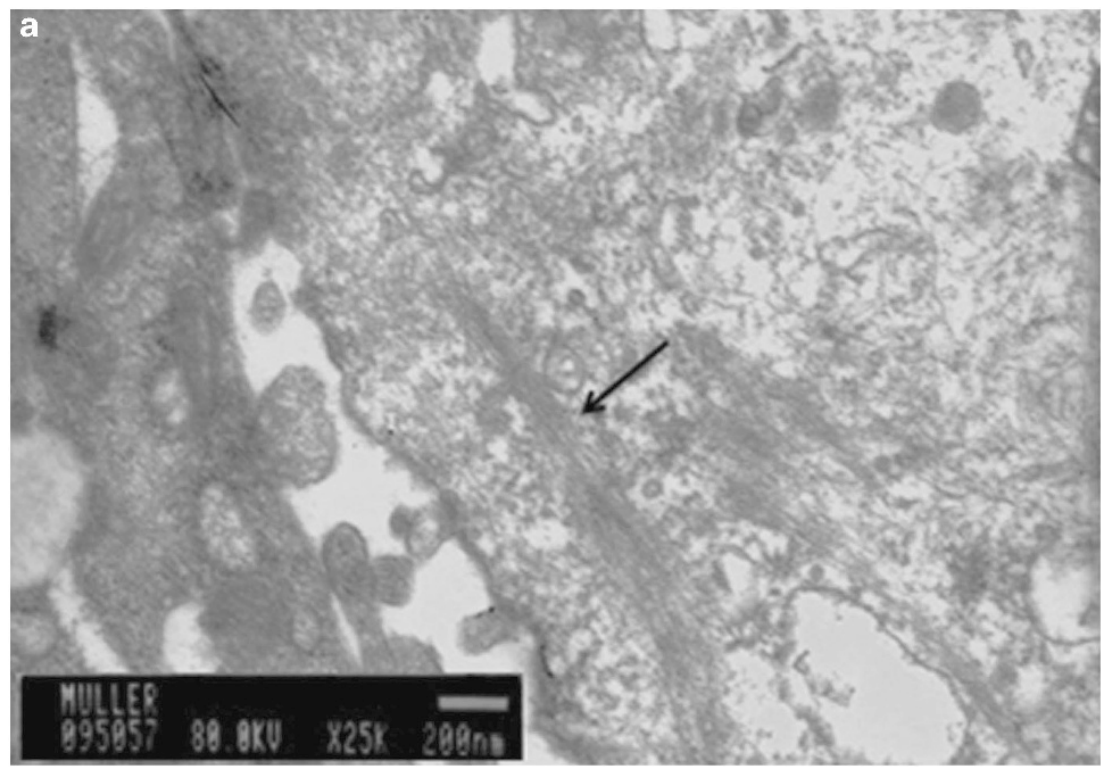

b

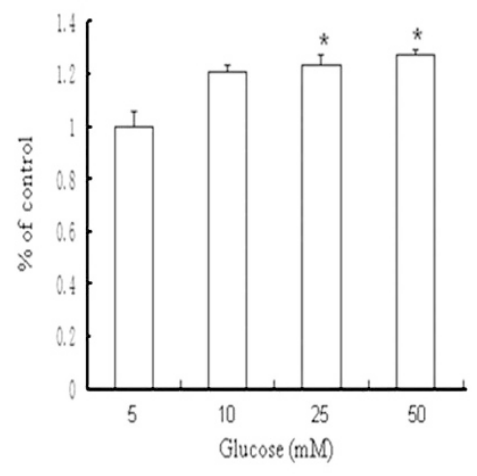

C

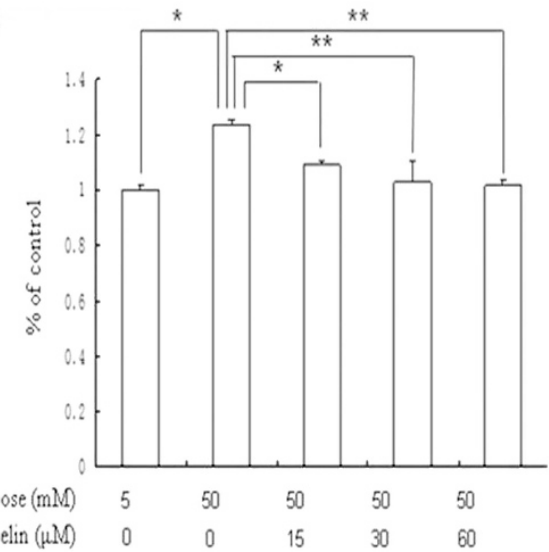

Figure 1 (a) A representative electron microscopic image of Müller cells. An intermediate filament, which is the hallmark of Müller cells, is indicated by a black arrow. Original magnification: $\times 25000$. Images were obtained using TEM (JEM-1200EX; JEOL, Tokyo, Japan). The effect of high-glucose conditions and embelin on Müller cell proliferation. (b) The percentage of viable cells increased with increasing glucose concentrations as compared with the controls ( $5 \mathrm{mM}$ glucose). (c) Embelin inhibited Müller cell growth in a dose-dependent manner even in the presence of high-glucose conditions $(50 \mathrm{mM})$. The experiment was repeated three independent times. Bars indicate SD. ${ }^{*} P<0.05$ and ${ }^{* *} P<0.01$.

isolates 20 channels across the membrane (Bio-Rad, Hercules, CA, USA). Two primary antibodies were added to each channel and allowed to bind to the proteins overnight at $4{ }^{\circ} \mathrm{C}$. Different sets of antibodies were used for each membrane (Table 1). The blot was washed and incubated with secondary horseradish peroxidase-conjugated antibodies (Bio-Rad) at room temperature for $1 \mathrm{~h}$. The membrane was developed with chemiluminescence substrate (Immun-Star HRP Peroxide Buffer/Immun-Star HRP Luminol Enhancer; Bio-Rad), and the chemiluminescence signals were captured using the ChemiDoc XRS System (Bio-Rad). Differences in protein level were determined by densitometric scanning (Quantity One software package; Bio-Rad) and normalized using internal standards.

\section{Western blot analysis}

Müller cells were washed twice with cold PBS after incubation with various concentrations of glucose $(5,10$, 25 , and $50 \mathrm{mM})$ and/or embelin $(0,15,30$, and $60 \mu \mathrm{M})$ at $37^{\circ} \mathrm{C}$ for $72 \mathrm{~h}$. Total cellular proteins were extracted as described above. Next, $20 \mu \mathrm{g}$ of each protein sample was fractionated by electrophoresis through a $10 \%$ SDS-PAGE, and then the proteins were transferred onto a nitrocellulose membrane. The membrane was incubated 
Table 1 List of proteins detected by antibodies used in the protein pathway array (PPA)

Phosphorylated proteins

$\mathrm{p}-\mathrm{PKC} \alpha, \mathrm{p}-\mathrm{PDK} 1, \mathrm{p}-\mathrm{PKC} \underline{\alpha / \beta \mathrm{II}}, \mathrm{p}-\mathrm{p} 53, \mathrm{p}-\mathrm{Akt}, \mathrm{p}-\mathrm{PTEN}, \mathrm{p}-\mathrm{RB}$, $\mathrm{p}$ - $\beta$-catenin, $\mathrm{p}$-c-Iun, p-Stat $3, \mathrm{p}$-ERK, p-GSK-3 $\alpha / \beta, \mathrm{p}-\mathrm{p} 70$

S6 kinase, p-eIF4B, p-HGFR, p-Smad, p-ERK5, p-p90RSK, p-CREB, p-PKC $\delta$, p-FAK, p-cdc2, p-Stat5, and p-p38

Nonphosphorylated proteins

FAS, FOXM1, Syk, MetRS, Twist, Lyn, KLF6, CaMKK $\alpha$, SK3, Stat1, cyclin B1, cyclin D1, Cdk6, Cdc25B, cyclin E, Cdk2 p27, TDP1， Cdk4, HER2, 14-3-3 $\beta$, cPKC $\alpha$, ERK, EGFR, SLUG, $\underline{\text { Cdc25C, Hsp90, CHK1 }}$ MDM2, Cdc2 p34, E2F-1, PCNA, p63, p38, Rap 1, $\beta$-catenin, Akt, $\underline{\text { HCAM}}, \underline{\text { XIAP }} \underline{\mathrm{Bcl}-2}$, patched, HIF- $1 \alpha$, HIF-2 $\alpha$, TTF-1, p53, Notch4, PTEN, SRC-1, Eg5, HIF-3 $\alpha$, Bax, N-cadherin, TNF- $\alpha$, Cdc42, eIF4B, vimentin, OPN, survivin, E-cadherin, TGF- $\beta$, ER $\beta$, WT1, mesothelin, VEGF, ATF-1, Ep-CAM, Bad, NF $\kappa$ B52, NF $\kappa$ B p50, calretinin, IL-1 $\beta$, $\underline{\text { H-Ras, }} \underline{\mathrm{Bcl}-6}$, K-Ras, $\alpha$-tubulin, NFkB p65, CREB, BID, maspin, DRG1, factor XIII B, IGFBP5, HCAM, ICAM-1, ER $\alpha$, c-Flip, PSM, Rab 7, VCAM-1, FGF-8, NEP, Bcl-xL, endoglin, Bak, TFIIH p89, Nkx-3.1, RIP NM23, c-IAP2, Epo, uPA, PDEF, Stat 3, ERCC1, uPAR, KAI1, L-selectin, PSCA, and E-selectin

Underlines indicate the proteins detected in Müller cells.

with the primary antibodies, including XIAP ( $1: 250$ dilution; BD Biosciences, San Jose, CA, USA) and VEGF (1:1000 dilution; Santa Cruz Biotechnology, Santa Cruz, CA, USA) at $4{ }^{\circ} \mathrm{C}$ overnight. The membrane was then incubated with a secondary anti-rabbit antibody conjugated with horseradish peroxidase (Amersham, Arlington Heights, IL, USA), the protein was detected using the chemiluminescence method, and chemiluminescent signals were captured using the ChemiDoc XRS System (Bio-Rad). The same membrane was then blotted using a monoclonal anti- $\beta$-actin antibody (1:10000 dilution; Sigma). The signal of each protein was determined by densitometric scanning (Quantity One software package; Bio-Rad).

\section{Signaling network analysis}

To investigate the biological functional relationship among the proteins, we used Ingenuity Pathway Analysis (IPA), an internet-based program (http:/ / www.ingenuity.com). Significantly, differentially expressed proteins $(P<0.05)$ identified by PPA were imported to IPA for functional analysis of the canonical pathways. Based on the Ingenuity Pathway Knowledge database of known interactions from the literature, the IPA program searched already-known molecular interactions among the uploaded genes and finally generated a new network. Functional analysis identified the biological functions and/or diseases that were most significant to the data set. Statistical significance was determined by Fisher's exact test, followed by multiple testing corrections by the Benjamini and Hochberg False Discovery Rate method. Proteins were represented as nodes, and the biological relationship between two nodes was represented as a line supported by at least one reference.

\section{Statistical analysis}

All culture experiments were performed in triplicate at three independent times. Western blot experiments were repeated three independent times, and PPA was repeated twice. Data were expressed as mean \pm SD. Statistical analysis of the results was performed using the Student's $t$-test and one-way analysis of variance. Unsupervised hierarchical clustering analysis was performed using BRB Array Tools software v.3.3.0 (http:/ /linus.nci.nih.gov/ BRB-ArrayTools.html). A significance level was set at $P<0.05$.

\section{Results}

\section{High-glucose conditions stimulated Müller cell proliferation}

It has been previously reported that diabetic animals have more Müller cells, which suggests a proproliferative effect of glucose. ${ }^{16}$ Therefore, we examined the effect of high-glucose conditions on Müller cell growth using the MTT assay and found a dosedependent increase of Müller cells after $72 \mathrm{~h}$ of incubation with various concentrations of glucose (up to $50 \mathrm{mM}$ ) (Figure 1b).

\section{High-glucose conditions altered the expression of regulatory proteins in Müller cells}

To better understand the molecular mechanisms of glucose-induced Müller cell proliferation, we performed global screening of regulatory protein expression using powerful PPA analysis. ${ }^{14,15}$ Müller cells were treated with physiological $(5 \mathrm{mM})$ and high-glucose $(50 \mathrm{mM})$ conditions for $72 \mathrm{~h}$, and the expressions of proteins and phosphoproteins were analyzed using PPA. Among 146 tested proteins and phosphoproteins, 108 were detected in protein samples from either the high- or normalglucose treatments (Table 1). Of these, 47 showed a significant difference in expression between cells treated with high-glucose $(50 \mathrm{mM})$ and normal-glucose $(5 \mathrm{mM})$ conditions based on the paired $t$-test $(P<0.05)$ and fold change $(>1.5)$ results (Figure $3 a)$. Forty proteins and phosphoproteins were overexpressed in high-glucosetreated cells. These 47 proteins are involved in several important signaling pathways based on IPA. These data suggest that high-glucose conditions cause a broad 


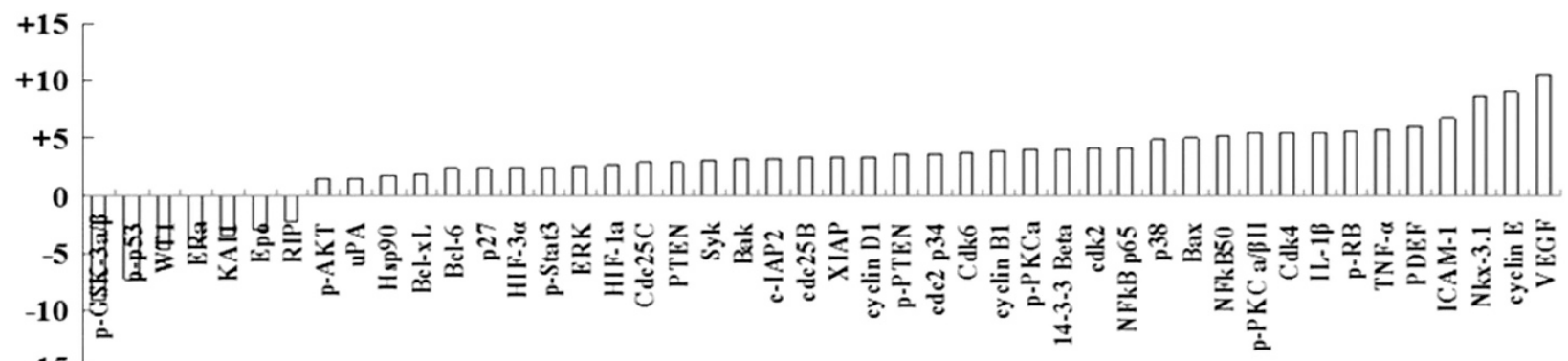

$-15$

A. Glucose $(50 \mathrm{mM})$

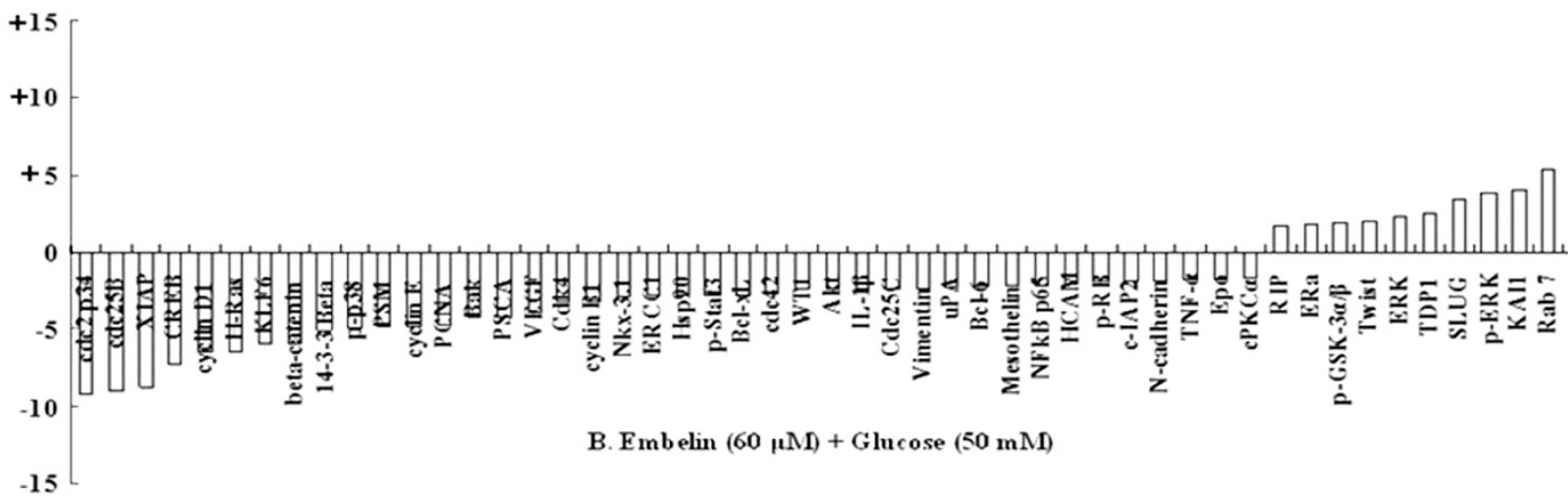

Figure 2 Ratio of protein expression in glucose- and embelin-treated Müller cells. (a) The expression of 47 out of 146 proteins/ phosphoproteins was altered after treatment with high-glucose conditions $(50 \mathrm{mM})$ for $72 \mathrm{~h}$ (compared with cells in a normal-glucose concentration, ie, $5 \mathrm{mM}$ ). (b) The expression of 50 out of 146 proteins/phosphoproteins was altered after treatment with high-glucose conditions $(50 \mathrm{mM})$ and embelin $(60 \mu \mathrm{M})$ for $72 \mathrm{~h}$ (compared with cells in physiological glucose conditions, ie, $5 \mathrm{mM}$ ). The numbers indicate fold change in protein expression between treated cells and control cells. ' + ' indicates increased expression. ' - ' indicates reduced expression.

dysregulation of the signaling pathways in Müller cells, which may collectively enhance Müller cell survival and proliferation.

\section{Embelin reversed the proliferation and protein expression alteration induced by high-glucose conditions}

The above results demonstrated that XIAP was one of the proteins significantly upregulated after high-glucose treatment (3.33 fold, $P<0.05$ ). Next, we investigated the role of XIAP in regulating Müller cell survival and proliferation. XIAP prevents cells from entering apoptosis in the presence of stress by blocking the apoptosis pathway. Embelin is a small molecule that specifically inhibits XIAP. ${ }^{17}$ Müller cells were incubated with various concentrations of embelin in the presence of high-glucose conditions $(50 \mathrm{mM})$, and the viable cells were determined by the MTT assay. The results showed that embelin reversed the pro-proliferative effect of highglucose conditions in a dose-dependent manner (Figure 1c). However, there was no significant increase of cell death even at $60 \mu \mathrm{M}$ embelin, as evident by the fact that the percentage of viable cells treated with embelin was similar to those treated with normal glucose, suggesting that embelin does not significantly affect Müller cell apoptosis.

As embelin can reverse high-glucose-induced proliferation, it is of great interest to see if embelin can correct the dysregulated signaling pathways induced by high-glucose conditions in Müller cells. Müller cells were treated with $60 \mu \mathrm{M}$ embelin in the presence of $50 \mathrm{mM}$ glucose for $72 \mathrm{~h}$, and the protein expression profile was analyzed using PPA. A total of 50 proteins showed significant changes $(P<0.05$ and $>1.5$ fold changes) as compared with the controls ( $50 \mathrm{mM}$ glucose) (Figure $2 \mathrm{~b}$ ). Of these 50 proteins, 41 proteins were downregulated. These proteins are involved in the same pathways that were affected by high-glucose conditions based on IPA. Furthermore, the expression levels of 26 out of 50 proteins and phosphoproteins (52\%), including XIAP and VEGF, were restored by embelin treatment (Figure 4a). These data suggest that embelin can reverse the effect of high-glucose conditions on protein expression in Müller cells. 


\section{XIAP regulated the expression of VEGF in Müller cells}

The above PPA results demonstrated a strong correlation between XIAP and VEGF expression in Müller cells, that is, both XIAP and VEGF expression increased with highglucose treatment $\left(R^{2}=0.911, P=0.012\right)$ (Figures 2a and $4 a)$, and inhibition of XIAP by embelin also led to a decrease of VEGF expression (Figures $2 b$ and $4 a$ ). To confirm this co-expression relationship, Müller cells were treated with increasing glucose concentrations $(5,25$, and $50 \mathrm{mM}$ ) for $72 \mathrm{~h}$, and the expression levels of VEGF and XIAP were examined using conventional western blot analysis. The results showed $>2$-fold increase at $25 \mathrm{mM}$ glucose and $>3$-fold increase at $50 \mathrm{mM}$ glucose of both proteins in a dose-dependent manner, respectively (Figure 3a). This relationship was further examined by incubation of Müller cells with high-glucose conditions $(50 \mathrm{mM})$ and various concentrations of embelin (15, 30, and $60 \mu \mathrm{M})$ for $72 \mathrm{~h}$. The results showed that the decrease of XIAP expression by embelin led to a decrease of VEGF expression (Figure 3b).

To further investigate how XIAP regulates VEGF expression, we generated an interactive network, with the help of IPA, using the 26 proteins that were restored to normal expression levels by embelin treatment in the presence of high-glucose conditions (Figure 4a). The PPA results showed that nine proteins, including $\mathrm{NF} \kappa \mathrm{B}$ p65, p-p38, tumor necrosis factor- $\alpha$ (TNF- $\alpha)$, urokinase-type

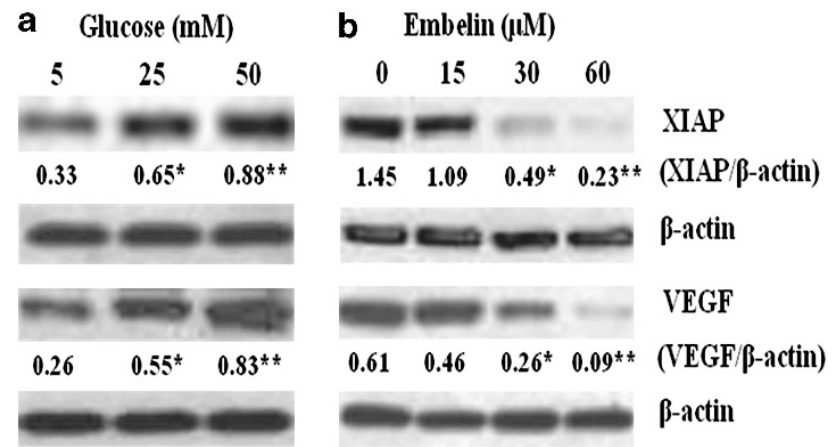

Figure 3 The effect of high-glucose conditions and embelin on the expression of XIAP and VEGF. (a) Western blot analysis showed increased expression levels of both XIAP and VEGF in Müller cells after $72 \mathrm{~h}$ incubation with increased concentrations of glucose. (b) Embelin inhibited the expressions of both XIAP and VEGF in Müller cells in a concentration-dependent manner.
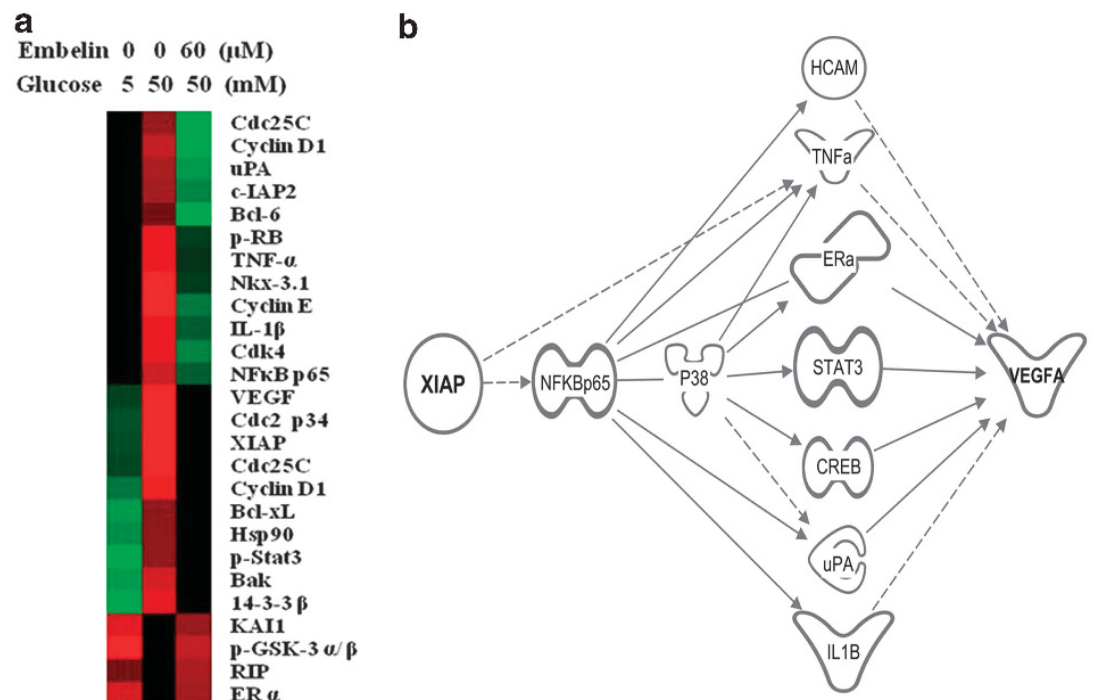

Figure 4 (a) Comparison of protein expression affected by high glucose and embelin using a heat map. The expression levels of 26 proteins were elevated under high-glucose conditions $(50 \mathrm{mM})$ and were reduced to normal levels by treatment with normal-glucose conditions $(5 \mathrm{mM})$ and embelin $(60 \mu \mathrm{M})$. Red scales indicate overexpression, green scales indicate underexpression, and black scales indicate an intermediate level of expression. (b) Proposed regulatory network between XIAP and VEGF. A regulatory network was generated using IPA by imputing proteins that were altered by high-glucose conditions but restored by embelin treatment. The network suggested that XIAP regulated VEGF expression via the NF $\kappa$ B/p38 pathways. Solid lines indicate a direct interaction. Dashed lines indicate an indirect interaction. Arrows indicate stimulation. 
plasminogen activator (uPA), CREB, IL-1 $\beta$, HCAM, estrogen receptor- $\alpha(E R \alpha)$, and p-Stat3, were involved in a regulatory network between XIAP and VEGF (Figure $4 b$ ). We hypothesize that XIAP may regulate VEGF mainly through the $\mathrm{NF} \kappa \mathrm{B}$ complex/p38 cascade pathways.

\section{Discussion}

Müller cells have an important role in the pathogenesis of diabetic retinopathy. The number of Müller cells is increased in patients with diabetes as a consequence of gliosis. ${ }^{10}$ Our results unequivocally showed that high-glucose conditions stimulated Müller cell proliferation, consistent with a previous report. ${ }^{16}$ Enhanced proliferation may be through dysregulation of several important signaling pathways in Müller cells. In the current study, the PPA and IPA data demonstrated that high-glucose conditions affected many canonical pathways including XIAP/apoptosis signaling, VEGF signaling, and cell cycle regulation, and so on. The dysregulation of these signaling pathways may collectively reduce apoptosis and enhance survival and proliferation of Müller cells. However, XIAP is probably the central mediator among these pathways and transmits the high-glucose signal to cell cycle progression (thus proliferation), because the inhibition of XIAP by embelin resulted in restoration of these pathways to normal levels and suppression of cell proliferation.

VEGF is one of the most potent angiogenic stimulators and vascular permeability factors. ${ }^{2,18}$ The Müller cell is an important source of VEGF in the retina, especially under hyperglycemic conditions. ${ }^{11}$ Our study confirmed that high-glucose conditions stimulated VEGF production in Müller cells, suggesting a regulatory role of glucose in VEGF expression. Young et al ${ }^{19}$ reported that intracellular VEGF protein in RPE cells was significantly increased under high-glucose conditions by regulating protein kinase $\mathrm{C}(\mathrm{PKC})$ isozymes. Wu et al ${ }^{20}$ reported that ERK5, a member of the MAPK family, contributes to high-glucose-elevated VEGF production in the retina via the MEF2-KLF2 pathway. It is worthy to note that both PKC $\alpha$ and $\operatorname{PKC} \beta$ were activated via phosphorylation and that ERK was upregulated in our study.

Here we reported another mechanism by which highglucose conditions regulate VEGF expression in Müller cells. The expression of XIAP strongly correlated with the expression of VEGF under high-glucose conditions, and inhibition of XIAP by embelin downregulated VEGF expression, suggesting a regulatory role of XIAP in glucose-induced VEGF expression. XIAP is a member of the inhibitor of apoptosis family, which consists of intrinsic cellular regulators of apoptosis. Recent studies indicate that IAPs not only regulate caspases and apoptosis but also modulate inflammatory signaling and immunity, mitogenic kinase signaling, proliferation, and mitosis. ${ }^{21}$ Although the exact regulatory mechanism is not clear, the IPA output suggests that a network of nine proteins (NF $\kappa$ B p65, p38, TNF- $\alpha$, uPA, CREB, IL- $1 \beta, \mathrm{ER} \alpha$, Stat3, and HCAM) is involved in the regulation of VEGF expression by XIAP. These data also suggest that XIAP indirectly interacts with the $\mathrm{NF} \kappa \mathrm{B}$ complex (a nuclear transcription factor with several subunits including p50/52/65), which regulates downstream proteins including p38 (a class of mitogen-activated protein kinases), HCAM (also known as CD44, a membrane receptor), TNF- $\alpha, \mathrm{ER} \alpha, \mathrm{uPA}$, a serine protease, and IL- $1 \beta$ (a member of the interleukin 1 cytokine family involved in cell proliferation, differentiation, and apoptosis). In addition, p38 regulates additional proteins including the signal transducer and activator of transcription 3 (STAT3) and cAMP response element-binding protein (CREB), which may further amplify the effect of XIAP on VEGF. Several lines of evidence support this regulatory network. For example, recent reports show that XIAP regulates ubiquitin-dependent activation of $\mathrm{I} \kappa \mathrm{B}$ kinase via its RING finger, which then activates $\mathrm{NF} \kappa \mathrm{B} .{ }^{21}$ Through the canonical and noncanonical signaling pathways, $\mathrm{NF} \kappa \mathrm{B}$ drives the expression of many downstream genes including $\mathrm{UPA},{ }^{22} \mathrm{IL}-1 \beta,{ }^{23} \mathrm{CREB}$, and TNF- $\alpha{ }^{24-26}$ These proteins can, in turn, increase the expression of VEGF. $^{26-28}$ A positive feedback loop may also exist between XIAP and VEGF, because it has been reported that VEGF can also enhance the expression of XIAP. ${ }^{29}$ This positive feedback loop can further increase the production of VEGF and promote Müller cell proliferation.

As XIAP is critical in mediating the effect of glucose on Müller cell proliferation and VEGF production, it could be a potential target for treating diabetic retinopathy. Embelin, a major constituent of embelia ribes, is a cellpermeable, small molecular inhibitor of XIAP. ${ }^{17}$ Embelin has been shown to have anti-tumor, anti-inflammatory, and analgesic properties. ${ }^{30}$ Our study showed that embelin counteracted the glucose-related stimulatory effect on the proliferation and production of VEGF in Müller cells, supporting the use of embelin in the treatment of diabetic retinopathy. In fact, recent animal studies have shown that embelin has a strong antidiabetic effect in alloxan-induced diabetic rats, as evident by a reduction in fasting blood glucose levels, significant improvement in body weights, and restoration of biochemical parameters. ${ }^{31}$ Importantly, no toxicity was observed in rats receiving embelin orally at doses of 25 and $50 \mathrm{mg} / \mathrm{kg}$ b.w.

In summary, XIAP is a central regulator that mediates high-glucose-induced pathological changes in Müller cells, and embelin would be an excellent candidate agent 
to target XIAP to prevent and treat diabetic retinopathy. Future studies will focus on investigating the molecular action of embelin and its pharmacodynamic and pharmacokinetic profiles to support future clinical trials.

\section{Summary}

What was known before

- Müller cells have important roles in the pathogenesis of diabetic retinopathy by promoting cell proliferation and inducing the production of vascular endothelial growth factor (VEGF) under hyperglycemic conditions. The objective of this study was to determine the potential mechanism of Müller cell proliferation and VEGF production due to high-glucose conditions.

\section{What this study adds}

- The current study suggests that XIAP may be a potential regulator that can mediate a series of pathological changes induced by high-glucose conditions in Müller cells. Therefore, embelin could be a potential agent for the prevention and treatment of diabetic retinopathy.

\section{Conflict of interest}

The authors declare no conflict of interest.

\section{Acknowledgements}

This study was partially supported by a grant from the National Science Foundation (No. 81070736) to E Song. The authors are grateful for Drs Jianhua Liu and Boxun Xie for their kind technical support.

\section{Author contributions}

DZ, ES, and FY contributed equally to this work by conceiving the hypothesis and overall study design. YS, DZ, and FY contributed equally to the experimental design, and DW and YS contributed equally by performing the protein pathway array assay. YS, XL, and LZ contributed equally to cell preparation. LG and YS contributed equally to the protein preparation. YS, DW and FY contributed equally to statistical analysis, and YS and DW contributed equally to summarizing the final data. YS and DZ contributed equally in preparing the manuscript.

\section{References}

1 Shah CP, Chen C. Review of therapeutic advances in diabetic retinopathy. Ther Adv Endocrinol Metab 2011; 2(1): 39-53.

2 Miller JW, Le Couter J, Strauss EC, Ferrara N. Vascular endothelial growth factor a in intraocular vascular disease. Ophthalmology 2013; 120(1): 106-114.
3 Gupta N, Mansoor S, Sharma A, Sapkal A, Sheth J, Falatoonzadeh $\mathrm{P}$ et al. Diabetic retinopathy and VEGF. Open Ophthalmol J 2013; 7: 4-10.

4 Kieran MW, Kalluri R, Cho YJ. The VEGF pathway in cancer and disease: responses, resistance, and the path forward. Cold Spring Harb Perspect Med 2012; 2(12): a006593.

5 Andreoli CM, Miller JW. Anti-vascular endothelial growth factor therapy for ocular neovascular disease. Curr Opin Ophthalmol 2007; 18(6): 502-508.

6 Reichenbach A, Bringmann A. New functions of Müller cells. Glia 2013; 61(5): 651-678.

7 Bringmann A, Wiedemann P. Müller glial cells in retinal disease. Ophthalmologica 2012; 227(1): 1-19.

8 Nelson CM, Hyde DR. Müller glia as a source of neuronal progenitor cells to regenerate the damaged zebrafish retina. Adv Exp Med Biol 2012; 723: 425-430.

9 Hu LM, Luo Y, Zhang J, Lei X, Shen J, Wu Y et al. EPO reduces reactive gliosis and stimulates neurotrophin expression in Muller cells. Front Biosci (Elite Ed) 2011; 3: 1541-1555.

10 Ulbricht E, Pannicke T, Uhlmann S, Wiedemann P, Reichenbach A, Francke M. Activation of retinal microglial cells is not associated with Müller cell reactivity in vitrectomized rabbit eyes. Acta Ophthalmol 2013; 91(1): e48-e55.

11 Brooks SE, Gu X, Kaufmann PM, Marcus DM, Caldwell RB. Modulation of VEGF production by $\mathrm{pH}$ and glucose in retinal müller cells. Curr Eye Res 1998; 17(9): 875-882.

12 Bai Y, Ma JX, Guo J, Wang J, Zhu M, Chen Y et al. Müller cell-derived VEGF is a significant contributor to retinal neovascularization. J Pathol 2009; 219(4): 446-454.

13 Hicks D, Courtois Y. The growth and behaviour of rat retinal müller cells in vitro. 1 . An improved method for isolation and culture. Exp Eye Res 1990; 51(2): 119-129.

14 Ye F, Che Y, McMillen E, Gorski J, Brodman D, Saw D et al. The effect of scutellaria baicalensis on the signaling network in hepatocellular carcinoma cells. Nutr Cancer 2009; 61(4): 530-537.

15 Zhang DY, Ye F, Gao L, Liu X, Zhao X, Che Y et al. Proteomics, pathway array and signaling network-based medicine in cancer. Cell Div 2009; 4: 20.

16 Rungger-Brandle E, Dosso AA, Leuenberger PM. Glial reactivity, an early feature of diabetic retinopathy. Invest Ophthalmol Vis Sci 2000; 41(7): 1971-1980.

17 Nikolovska-Coleska Z, Xu L, Hu Z, Tomita Y, Li P, Roller PP et al. Discovery of embelin as a cell-permeable, smallmolecular weight inhibitor of XIAP through structure-based computational screening of a traditional herbal medicine three-dimensional structure database. J Med Chem 2004; 47(10): 2430-2440.

18 Bhisitkul RB. Vascular endothelial growth factor biology: clinical implications for ocular treatments. Br J Ophthalmol 2006; 90(12): 1542-1547.

19 Young TA, Wang H, Munk S, Hammoudi DS, Young DS, Mandelcorn MS et al. Vascular endothelial growth factor expression and secretion by retinal pigment epithelial cells in high glucose and hypoxia is protein kinase C-dependent. Exp Eye Res 2005; 80(5): 651-662.

20 Wu Y, Zuo Y, Chakrabarti R, Feng B, Chen S, Chakrabarti S. ERK5 contributes to VEGF alteration in diabetic retinopathy. J Ophthalmol 2010; 2010: 465824.

21 Gyrd-Hansen M, Meier P. IAPs: from caspase inhibitors to modulators of NF-kappaB, inflammation and cancer. Nat Rev Cancer 2010; 10(8): 561-574. 
22 Wang W, Abbruzzese JL, Evans DB, Chiao PJ. Overexpression of urokinase-type plasminogen activator in pancreatic adenocarcinoma is regulated by constitutively activated RelA. Oncogene 1999; 18(32): 4554-4563.

23 Wang J, Wang X, Hussain S, Zheng Y, Sanjabi S, Ouaaz $\mathrm{F}$ et al. Distinct roles of different NF-kappa B subunits in regulating inflammatory and $\mathrm{T}$ cell stimulatory gene expression in dendritic cells. J Immunol 2007; 178(11): 6777-6788.

24 Baldari CT, Tonello F, Paccani SR, Montecucco C. Anthrax toxins: A paradigm of bacterial immune suppression. Trends Immunol 2006; 27(9): 434-440.

25 Gaither A, Porter D, Yao Y, Borawski J, Yang G, Donovan $\mathrm{J}$ et al. A smac mimetic rescue screen reveals roles for inhibitor of apoptosis proteins in tumor necrosis factoralpha signaling. Cancer Res 2007; 67(24): 11493-11498.

26 Ameglio F, D'Auria L, Cordiali-Fei P, Mussi A, Valenzano L, D'Agosto G et al. Bullous pemphigoid and pemphigus vulgaris: correlated behaviour of serum VEGF, sE-selectin and TNF-alpha levels. J Biol Regul Homeost Agents 1997; 11(4): 148-153.
27 Lemberger T, Parkitna JR, Chai M, Schütz G, Engblom D. CREB has a context-dependent role in activity-regulated transcription and maintains neuronal cholesterol homeostasis. FASEB J 2008; 22(8): 2872-2879.

28 Plouët J, Moro F, Bertagnolli S, Coldeboeuf N, Mazarguil H, Clamens $S$ et al. Extracellular cleavage of the vascular endothelial growth factor 189-amino acid form by urokinase is required for its mitogenic effect. J Biol Chem 1997; 272(20): 13390-13396.

29 Tran J, Rak J, Sheehan C, Saibil SD, LaCasse E, Korneluk RG et al. Marked induction of the IAP family antiapoptotic proteins survivin and XIAP by VEGF in vascular endothelial cells. Biochem Biophys Res Commun 1999; 264(3): 781-788.

30 Chitra M, Sukumar E, Suja V, Devi CS. Antitumor, anti-inflammatory and analgesic property of embelin, a plant product. Chemotherapy 1994; 40(2): 109-113.

31 Mahendran S, Badami S, Maithili V. Evaluation of antidiabetic effect of embelin from embelia ribes in alloxan induced diabetes in rats. Biomed Pharmacother 2011; 1(1): 25-31. 